\title{
Extending biodiversity conservation with functional and evolutionary diversity: a case study of South African sparid fishes
}

\section{R Henriques , BQ Mann , ES Nielsen , C Hui \& S von der Heyden}

To cite this article: R Henriques , BQ Mann , ES Nielsen , C Hui \& S von der Heyden (2020):

Extending biodiversity conservation with functional and evolutionary diversity: a case study of South African sparid fishes, African Journal of Marine Science, DOI: 10.2989/1814232X.2020.1798282

To link to this article: https://doi.org/10.2989/1814232X.2020.1798282

View supplementary material $₫$

\section{Published online: 22 Sep 2020.}

Submit your article to this journal $[\pi$

Џ Article views: 13

Q View related articles $\asymp$

View Crossmark data $\nearrow$ 


\title{
Extending biodiversity conservation with functional and evolutionary diversity: a case study of South African sparid fishes ${ }^{\S}$
}

\author{
R Henriques ${ }^{1,2 *}$ iD, BQ Mann ${ }^{3}$ iD, ES Nielsen ${ }^{1}$ (D), C Hui ${ }^{4}$ iD and S von der Heyden ${ }^{1}$ (iD \\ ${ }^{1}$ Evolutionary Genomics Group, Department of Botany and Zoology, Stellenbosch University, Stellenbosch, South Africa \\ 2 Technical University of Denmark - National Institute of Aquatic Resources (DTU Aqua), Silkeborg, Denmark \\ ${ }^{3}$ Oceanographic Research Institute (ORI), Durban, South Africa \\ ${ }^{4}$ Centre for Invasion Biology, Department of Mathematical Sciences, Stellenbosch University, and African Institute of \\ Mathematical Sciences, Stellenbosch, South Africa \\ *Corresponding author, e-mail: rhenriques@sun.ac.za
}

\begin{abstract}
Designing marine protected area (MPA) networks has relied primarily on species- or habitat-based measures that assess spatial distributions of biodiversity. Molecular and functional data have the potential to unlock information regarding the evolutionary uniqueness and resilience of natural communities, making phylogenetic diversity (PD) and functional diversity (FD) effective tools for spatial planning. These are, however, rarely used in marine conservation planning. In South Africa, MPAs have been implemented to protect rare and valuable fishery resources, such as members of the Sparidae (seabreams), but have not considered different dimensions of biodiversity, such as its phylogenetic and functional components. Here, we mapped species distributions, phylogenetic relationships and functional features of the Sparidae in South Africa to refine how biodiversity is spatially structured for this species-rich taxonomic group. Our results show strong spatial similarities between PD and FD, suggesting that, for this group, PD is an effective surrogate for functional data. However, there was a mismatch between areas selected with different biodiversity metrics (particularly endemicity levels) and established MPAs, highlighting the need for integrated approaches to conserve this unique marine fauna.
\end{abstract}

Keywords: biodiversity metrics, biodiversity surrogates, functional diversity, marine protected areas, marine spatial planning, phylogenetic diversity, Sparidae

Online supplementary material: A list of all sparid species present in South Africa, with GenBank accession numbers (Table S1) and the functional traits considered (Table S2), as well as the phylogenetic tree (Figure S1) and functional dendrogram (Figure S2) used in this work, are available at https://doi.org/10.2989/1814232X.2020.1798282.

Introduction

The vulnerability of marine ecosystems to ongoing anthropogenic pressures is well documented, as is the efficacy of marine protected areas (MPAs) for slowing such impacts (Roberts et al. 2017). For example, well-enforced no-take MPAs can contribute to increased abundance levels, mean sizes and diversity of focal species (Spalding et al. 2008; Kerwath et al. 2013), as well as to the resilience of ecosystems (Ling et al. 2009; Mellin et al. 2016). To date, most marine conservation efforts have relied on species-, habitat- or socioeconomic-based metrics to inform the size, design and geographic location of MPAs (Mouillot et al. 2011; D’Agata et al. 2014). Species richness and endemicity levels have been widely used as proxies for biodiversity, and most MPAs to date have been established to protect taxonomic diversity or conserve rare/

\$This article is based on a paper presented at the 5th Southern African Marine Linefish Symposium, held 8-11 July 2019, at Mpekweni Beach Resort, Eastern Cape, South Africa, and is part of the special issue 'Linefish resilience in the Anthropocene,' edited by WM Potts, CG Attwood and PD Cowley valuable species (Edgar et al. 2014; Selig et al. 2014). In particular, regions with high levels of endemism (endemic hotspots) have been pivotal in the establishment of MPAs, as endemic species are considered to be of greater extinction risk (Dulvy et al. 2014; Pimm et al. 2014; Selig et al. 2014). However, these metrics do not necessarily capture the sum of the many components of biodiversity and may fail to reflect unique evolutionary histories or ecosystem complexity (Winter et al. 2013; D'Agata et al. 2014; Wright et al. 2015). In particular, evolutionary diversity (phylogenetic diversity) and functional diversity, both important components recognised by the Convention on Biological Diversity (www.cbd.int), are often poorly accounted for in the management and conservation of biodiversity (Laikre et al. 2016; von der Heyden 2017).

Phylogenetic diversity (PD) and functional diversity (FD) are two vital metrics of biodiversity often overlooked in conservation planning. PD, defined as "the minimum total length of all phylogenetic branches required to span a given set of taxa on the phylogenetic tree" (Faith 1992, p 4), is a community-based metric that explains evolutionary history 
contained and shared between communities (Winter et al. 2013). This allows for the identification and preservation of genetically and evolutionarily unique areas (D'Agata et al. 2014; Huang and Roy 2015). Similarly, FD, defined as the "total branch length of a functional dendrogram" (Petchey and Gaston 2002, p 404), can be interpreted as an indicator of ecosystem dynamics, productivity and stability, where communities with higher FD are expected to be more resilient to change and offer greater ecosystem services (Wiedmann et al. 2014). Recent studies suggest that a loss of PD and FD reduces the potential of communities to respond to changing environmental conditions, both in marine ecosystems (Mouillot et al. 2011) and terrestrial ecosystems (Cadotte et al. 2011; Flynn et al. 2011; Le Bagousse-Pinguet et al. 2019). Globally, there is little geographic overlap between species richness (SR) or endemism (ED) and other biodiversity components, such as FD and PD. This mismatch leaves large swathes of the global ocean underrepresented in conservation efforts (Lindegren et al. 2018).

The oceanographic systems off the South African coast are among the most diverse in the world (Taunton-Clark and Shannon 1988). Bounded by the cold Benguela Current in the west and the warm Agulhas Current in the east (Driver et al. 2012), the approximately $3000-\mathrm{km}$ coastline harbours a highly biodiverse environment, spanning from cold-temperate kelp communities to subtropical coral reefs (Griffiths et al. 2010). The degree of protection of South African marine biodiversity through an established MPA network differs between offshore and inshore environments, with the inshore environment historically having had a greater level of protection. Similarly, there is a strong gradient of protection, with the east coast having a larger protection footprint than the south and west coasts (Sink et al. 2019). This west-east 'protection gradient' is thought to reflect a general trend of species richness, as richness increases eastwards into the subtropical region of the Indian Ocean (Turpie et al. 2000; Driver et al. 2012).

Several South African MPAs were implemented to protect important fishery resources (Mann et al. 2006), such as species of the family Sparidae. In South Africa, this family contains 24 genera and 41 species (Froese and Pauly 2016), 15 of which are in the near threatened or threatened categories of the IUCN Red List of Threatened Species (International Union for Conservation of Nature and Natural Resources, https://www.iucnredlist.org) (ComerosRaynal et al. 2016). Sparids occur along the entire South African coastline and represent a functionally diverse group. Species of this family are often slow-growing, late-maturing and display resident behaviour, making them exceptionally vulnerable to overfishing (Griffiths 2000; Comeros-Raynal et al. 2016). Years of intense harvesting have led to a significant decrease in abundance levels, with populations of many species now considered overexploited or collapsed (Mann 2013). Sparids are targeted by multiple users along the coastline, from commercial to recreational and small-scale fisheries. The combined fishing effort appears greatest off the southwest coast of South Africa, whereas recreational pressure tends to follow an increasing gradient from west to east (Majiedt et al. 2019).

Although several MPAs have been implemented to protect important sparid habitat (such as the Pondoland
MPA: Mann et al. 2006), little is known regarding their effectiveness in protecting the different components of biodiversity of this species-rich taxonomic group. Here, we utilise a suite of biodiversity metrics for the Sparidae (including SR, ED, PD and FD), and map these for coastal South Africa. We identify similarities and differences in the distribution of these biodiversity metrics along the coast, allowing us to detect regions that capture functional, ecological, and evolutionary aspects of sparids. The results are then overlaid onto the current coastal MPA network to identify possible gaps in spatial protection of this unique marine fauna.

\section{Methods}

Data on spatial distribution of species were obtained from available literature (i.e. Smith and Heemstra 1999; Heemstra and Heemstra 2004; Branch et al. 2010; Mann 2013; Froese and Pauly 2016). The coastline was gridded with a resolution of a quarter degree per cell (approximately $25 \times 27 \mathrm{~km}$ ) in QGIS 2.10.1 (QGIS 2015). Each grid cell was used to build presence-absence matrices of species occurrence and the number of endemics (i.e. species found only along the South African coastline, and thus not shared with any other country). It should be noted that this is a broad generalisation and is likely to overestimate true distribution ranges by including areas where certain species are absent (e.g. rocky-reef species in sandy-bottom areas). However, given the resolution of the chosen grid and that juveniles and adults of some species tend to occur in different habitats (Smith and Heemstra 1999; Heemstra and Heemstra 2004; Branch et al. 2010; Mann 2013; Froese and Pauly 2016), we considered this to be the most comprehensive and conservative approach.

SR was calculated as the total number of species per cell, while ED was calculated as the total number of South African endemic species per cell. To calculate PD as defined by Faith (1992), we amplified and sequenced a fragment of the cytochrome $c$ oxidase subunit I gene (COI) from mitochondrial DNA (mtDNA), following the protocol of Ivanova et al. (2007), and also used sequences available in GenBank (Supplementary Table S1). In total, we obtained sequence data for 40 of the 41 sparid species occurring in South Africa. Sequences were aligned in Geneious 9.0.5 (Kearse et al. 2012), and nucleotide substitution models were estimated in jModelTest (Posada 2008). Reconstruction of phylogenetic relationships was performed using 'maximum likelihood' in PhyML (Guindon et al. 2009). Branch support was assessed using the chi-square approximate likelihood ratio test $\left(\chi^{2}-\right.$ aLRT: Anisimova and Gascuel 2006$)$.

To estimate FD as defined by Petchey and Gaston (2002), we chose five main trait categories: (i) adult and juvenile habitat; (ii) biology and life history (e.g. movement, and length- and age-at-maturity); (iii) level of endemicity; (iv) feeding habits; and (v) IUCN threat level (Supplementary Tables S1 and S2), resulting in a matrix with 13 functional traits. While the IUCN Red List status is not a functional trait per se, it is essentially an estimate of population status and associated extinction risk for the species, being directly linked to their intrinsic 
behavioural and life-history characteristics. Estimates of PD and FD were obtained per grid cell, in the $R$ package 'picante' 2.1 (Kembel et al. 2010), as the total branch lengths spanned by the phylogenetic tree (or functional dendrogram) including all species in a local community. All obtained metrics were categorised into three ranks to distinguish between low (0-40\%), medium (41-75\%) and high (76-100\%) levels, and imported to QGIS 2.10.1 (QGIS 2015). Each metric was mapped separately as well as in a comparative framework to investigate mismatches between metrics. To understand the strength of correlation between each of the maps, shapefiles were converted to rasters using the 'rasterize' function of the R package 'raster' (Hijmans et al. 2015) and correlations were calculated using the R function 'cor'.

From a conservation perspective, regions where each biodiversity metric is maximised, and where these overlap, are of particular conservation importance (Margules and Pressey 2000). To plot this, we selected only the grid cells where the four metrics were classified as 'high' and overlaid these onto a map of the current coastal MPA network. This allowed us to identify regions of conservation interest and evaluate whether these are represented in the current network of MPAs.

\section{Results}

Of the 41 sparid species found in South African waters, 15 occur only there (excluding vagrants) and 14 are shared across the southern African region. SR differed along the coast, increasing from west $(n=6)$ to east $(n=35)$ (Figure 1a). Endemic species are concentrated off the south coast $(n=15)$ (Figure 1b). Reconstruction of the phylogenetic relationships based on $\mathrm{COI}$ retrieved a generally robust tree, although some terminal branches had support lower than $50 \%$ (Supplementary Figure S1). Spatial patterns of PD and FD were mainly identical, showing a west-east increase, starting from the southwest coast (Figure 1c-d).

The spatial comparison between SR, ED, PD and FD revealed differences among the geographic distributions of these metrics (Figure 2): the west coast was considered a coldspot for all metrics, as they were at their lowest in this region, whereas the south coast was identified as a hotspot for ED, and the east coast a hotspot for PD, FD and SR. Correlations show that FD, $P D$ and $S R$ are highly similar $(>0.96)$, with ED being the most distinct (0.62-0.7).

When compared with the existing coastal MPA network, not all biodiversity components were protected equally, with hotspots of SR, FD and PD falling within more MPAs on the east coast (47 of 84 grid cells [56\%]), compared with the area of high ED within the south coast (25 of 68 grid cells [37\%]) (Figure 1a-d). Interestingly, all four biodiversity metrics were at their highest on a stretch of coastline on the south to southeast coast, spanning the area from the Tsitsikamma MPA to the southern range of the Pondoland MPA (Figure 3). In this region, 14 of the $37(38 \%)$ grid cells were represented by MPAs, although only $12(32 \%)$ of the grid cells fell into MPAs with restricted no-take zones, where extractive activities are prohibited.

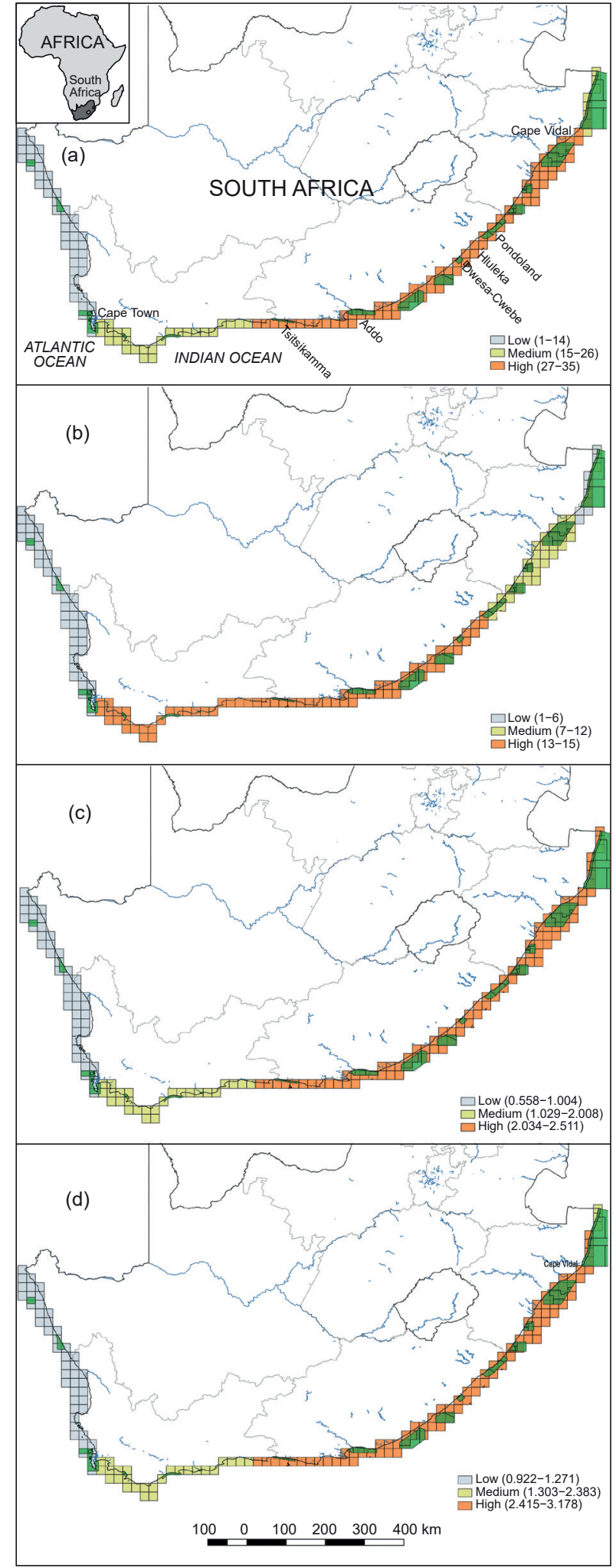

Figure 1: Spatial distribution of (a) species richness (SR), (b) endemism (ED), (c) phylogenetic diversity (PD), and (d) functional diversity (FD) metrics obtained for the Sparidae in South Africa. The current coastal marine protected areas in the region are shown in green. The colours of the grids reflect the rank of each biodiversity metric across the region 


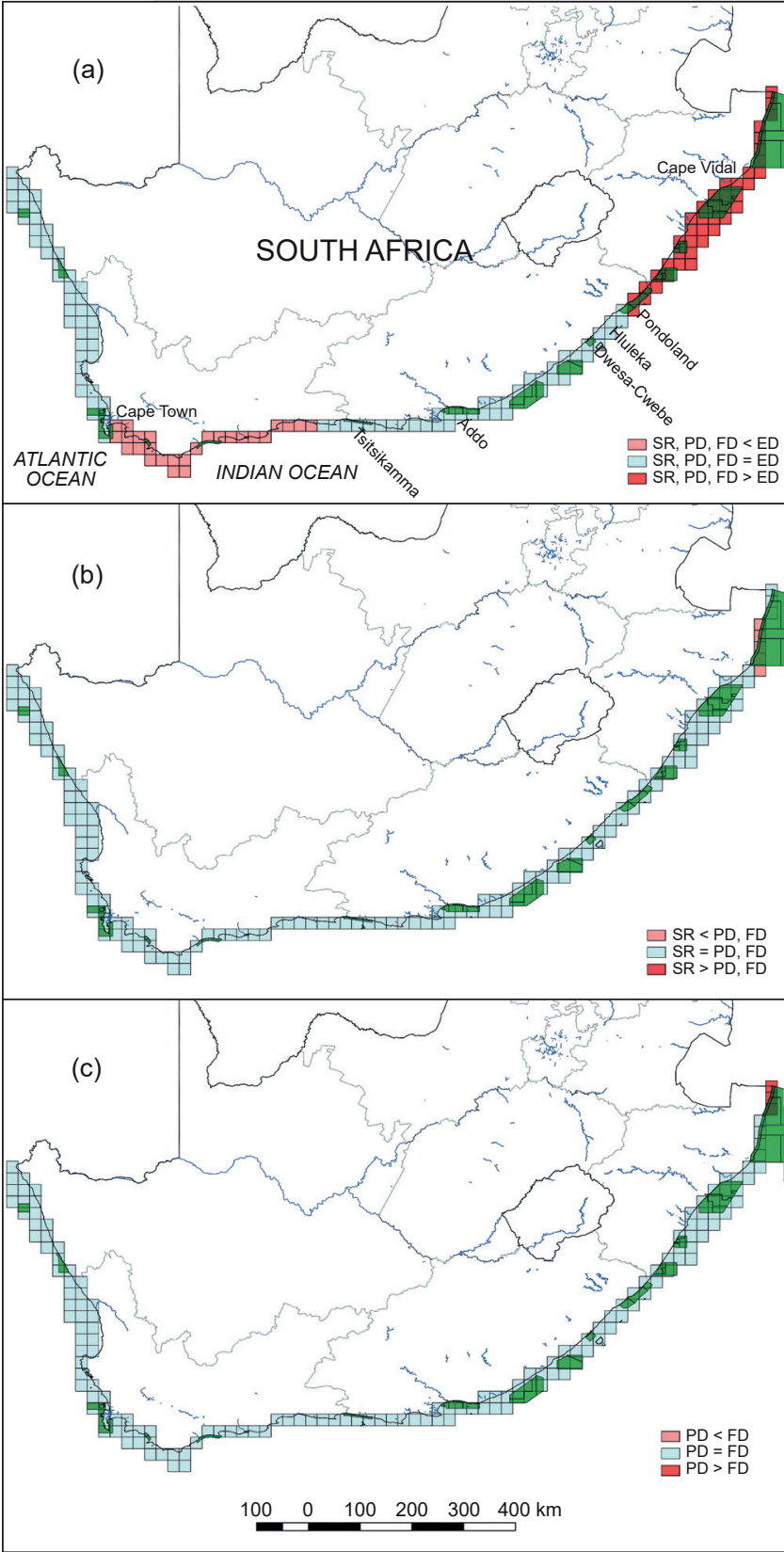

Figure 2: Spatial comparisons between (a) phylogenetic diversity (PD), functional diversity (FD) and species richness (SR) vs endemism (ED), (b) SR vs FD and SR vs PD, and (c) PD vs FD. The current coastal marine protected areas in the region are shown in green. The colours of the grids reflect the rank of each comparison between biodiversity metrics across the region

\section{Discussion}

The need to incorporate multiple measures of biodiversity when delineating conservation priorities has been discussed for more than 25 years (Faith 1992; Winter et al. 2013), and their importance is recognised by the Convention on Biological Diversity (www.cbd.int). Yet few applied examples exist from marine systems where molecular data have been utilised in addition to other conservation features (Mouillot

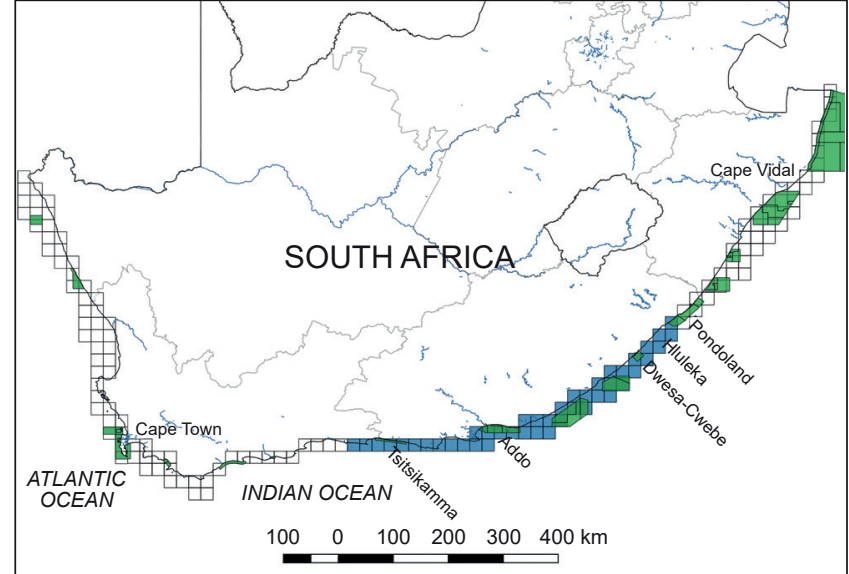

Figure 3: Areas of highest spatial overlap (shown in blue) of maximum species richness, endemism, phylogenetic diversity and functional diversity. Current coastal marine protected areas in the region are shown in green

et al. 2011; D'Agata et al. 2014; Parravicini et al. 2014; Huang and Roy 2015; Nielsen et al. 2017). As the loss of evolutionary diversity and functional complexity can occur at a faster pace than the decrease of SR (D'Agata et al. 2014), the PD and FD components of biodiversity are invaluable to conservation prioritisation (D'Agata et al. 2014; Huang and Roy 2015). Our study, on a commercially and biologically significant group of southern African fishes, adds to the growing body of evidence that suggests that using multiple metrics can highlight new areas for marine conservation planning, targeting all components of biodiversity.

\section{Biodiversity patterns of an iconic taxonomic group}

By using South African sparids it was possible to observe mismatches between areas with different levels of SR, ED, PD and FD along the South African coastline. Endemism in particular stood out; whereas FD, PD and SR all followed a trend of increasing from west to east, ED did not. For endemic species, the south coast was identified as a hotspot, and therefore a high-priority conservation area. While this region recently gained additional area-protection with the declaration of the Addo Elephant National Park MPA and the Amathole Offshore MPA (RSA 2019), it has lost effective area-protection with the opening up of parts of the Dwesa-Cwebe MPA (Venter and Mann 2012) and the Tsitsikamma MPA to shore fishing (Lombard et al. 2020). The higher level of endemicity in this region coincides spatially with the region of confluence between two oceanographic regimes, the Benguela Current and Agulhas Current, which creates a highly heterogeneous marine system (Driver et al. 2012). Environmental variability has been linked to radiation events in marine systems (Bernardi 2013) and may thus be a dominant evolutionary force driving speciation rates within South African sparids. Similarly, the observed higher ED but lower PD and FD in this region is likely to reflect the fact that the 15 endemic species correspond to only 12 genera, which are found in the same superclade and are closely related in the functional dendrogram (see Supplementary Figures S1 and S2). 
In general, there was a west-east increase of PD and FD, which was expected as these measures usually increase with the number of species (Winter et al. 2013; D'Agata et al. 2014; Pollock et al. 2015, but also see Forest et al. 2007). However, there was a mismatch north of Cape Vidal, as the number of species decreased, but PD and FD remained at maximum level. This may be explained by the fact that only 26 of the 41 species are present in this area, but these are well distributed throughout the phylogenetic tree and the functional dendrogram (Supplementary Figures S1 and S2) and correspond to 15 genera: Acanthopagrus, Argyrops, Cheimerius, Chrysoblephus, Crenidens, Diplodus, Lithognathus, Pachymetopon, Pagellus, Petrus, Polyamblyodon, Polysteganus, Porcostoma, Rhabdosargus and Sarpa. Furthermore, this area constitutes a biogeographic boundary region for the majority of temperate species, with a change in community composition towards more tropical taxa (Sink et al. 2019).

Interestingly, the PD and FD metrics were mostly identical (Pearson's $r=0.99$ ), reflecting the complexity of life-history features in the group. Sparids are long-lived, have complex reproductive behaviours and migration patterns, and occur in a great variety of habitats. Although the relationship between PD and FD is not always clear, in this case it appears that $P D$ is a valid surrogate for FD, as observed for other marine species (Mouillot et al. 2011; D'Agata et al. 2014; Huang and Roy 2015). In a rapidly changing marine environment, where not every species can be protected, conservation decisions should incorporate the most representative metrics of biodiversity. Gathering the necessary biological information to estimate FD is time- and resource-consuming (Dalleau et al. 2010) in comparison with the effort required for PD. In fact, studies show that even incomplete phylogenies can provide robust conservation outcomes (Rodrigues et al. 2011). Therefore, $P D$ is an effective and easy-to-use tool for conservation planning efforts, especially in marine systems, and should be further explored in a southern African context. Our findings are further corroborated by the observed spatial mismatch between the ED hotspot area (a metric generally used to represent uniqueness) and the regions with higher $P D$, suggesting that failure to target PD may lead to the loss of functionally and/or evolutionarily unique taxa (Scheffer et al. 2015). From a broader South African perspective, widening the use of PD to include more marine fishes would show similar patterns to the Sparidae as the South African fish fauna is dominated by Indo-Pacific species, with SR heavily skewed towards the east coast (Turpie et al. 2000). As such, we would expect higher levels of PD and FD along the eastern coastline, with exceptions for taxonomic groups with more unique distributions, such as the Clinidae, whose geographic centre lies around the southwestern Cape. We therefore recommend that future studies of PD, SR, ED and FD carefully consider their selection criteria to try and widen geographic coverage.

\section{Aligning biodiversity components with the extant MPA network}

Our results suggest that the established MPA network does not protect the full evolutionary and functional potential of this commercially important and highly diverse group. While the northern KwaZulu-Natal coast, an area characterised by high PD and FD, is well-protected, the south coast, an area with far fewer MPAs, requires additional protection to better represent endemic sparid species, especially since this area experiences the highest fishing pressures, both from commercial and recreational users (Majiedt et al. 2019). From a systematic-conservation-planning perspective, maximising the amount of biodiversity features captured in a limited amount of space is of particular importance. To this end, we identified parts of the southern and southeastern coastline, spanning approximately from the Tsitsikamma MPA to the southern Pondoland MPA (Figure 3). Interestingly, this aligns well with both biogeographic and phylogeographic boundaries (Teske et al. 2011; Sink et al. 2012), suggesting that both historical and contemporary processes have shaped and continue to shape the evolutionary trajectories of coastal fish communities. This region not only bounds the transition zone between the warm-temperate and subtropical ecoregions, but also incorporates regions of persistence for rocky shores and estuarine species. For example, Toms et al. (2014) showed that rocky shores persisted in eastern Algoa Bay throughout 75000 years of sea-level change, and Phair et al. (2019) provided evidence for environmental stability in the region throughout the Last Glacial Maximum and Holocene. As such, it is not surprising that biodiversity measures such as SR and PD are maximised here, as these are likely a result of spatiotemporal stability and persistence of suitable habitat.

From a conservation perspective, although the southern and southeastern coastline is reasonably well covered by a number of coastal MPAs, they are all designed for multiple use with only parts zoned for no-take. One major recommendation from our work is that a greater area within this region needs to be zoned for no-take (i.e. closed to fishing activities) in order to protect sparids. Strengthening no-take area protection in the Tsitsikamma and Dwesa-Cwebe MPAs and expanding the extent of the Hluleka MPA, for example, would be important steps to take in this regard. In addition, MPAs provide opportunities for maintaining complex and functioning ecosystems (Heyns-Veale et al. 2019), which in turn will help promote recruitment and survival of juvenile stages, thus promoting overall resilience of sparids to future climatic changes. However, given the potential redistribution of marine fishes in South Africa owing to climate change (James et al. 2013; Potts et al. 2015), as well as globally (Morley et al. 2018), it is imperative that PD and endemicity are monitored on an ongoing basis. As species distributions potentially shift at different rates, novel combinations of functional traits and evolutionary diversities may emerge, which will be important to monitor to evaluate MPA effectiveness for adaptive management. This is likely to affect entire communities, so it is advisable that other functionally and phylogenetically diverse taxa be included in scenarios of planning and evaluating future protected areas. In particular, our results suggest that the current mismatch between protection measures and levels of endemism should be addressed, as endemic sparid species are more vulnerable to ongoing climate change in the region because of narrower distribution ranges and mainly sedentary life histories (Comeros-Raynal et al. 2016). Therefore, 
increased protection should be enforced across the south coast of South Africa. Overall, our findings have important implications for future conservation-planning scenarios that also include considerations for anthropogenic and climatedriven changes.

Acknowledgements - We thank the South African Institute for Aquatic Biodiversity (SAIAB) for the loan of tissue samples; voucher specimens used are listed in the online supplementary material. This work was funded by grant no. 86957 through the Foundational Biodiversity Information Programme to SvdH. RH was funded by a Claude Leon Foundation postdoctoral grant. $\mathrm{CH}$ was supported by the National Research Foundation of South Africa (grant no. 89967). The authors declare no competing interests.

\section{ORCID}

Romina Henriques: https://orcid.org/0000-0002-6544-5532

Cang Hui: https://orcid.org/0000-0002-3660-8160

Bruce Q Mann: https://orcid.org/0000-0002-7130-6301

Erica S Nielsen: https://orcid.org/0000-0002-5439-571X

Sophie von der Heyden: https://orcid.org/0000-0001-9166-976X

\section{References}

Anisimova M, Gascuel O. 2006. Approximate likelihood-ratio test for branches: a fast, accurate, and powerful alternative. Systematic Biology 55: 539-552.

Bernardi G. 2013. Speciation in fishes. Molecular Ecology 22: 5487-5502.

Branch GM, Griffiths CL, Branch ML, Beckley LE. 2010. Two oceans: a guide to the marine life of southern Africa. Cape Town, South Africa: Struik Nature.

Cadotte MW, Dinnage R, Tilman D. 2011. Phylogenetic diversity promotes ecosystem stability. Ecology 93: 223-233.

Comeros-Raynal MT, Polidoro BA, Broatch J, Mann BQ, Gorman C, Buxton CD et al. 2016. Key predictors of extinction risk in sea breams and porgies (Family: Sparidae). Biological Conservation 202: 88-98.

D’Agata S, Mouillot D, Kulbicki M, Andréfouët S, Bellwood DR, Cinner JE et al. 2014. Human-mediated loss of phylogenetic and functional diversity in coral reef fishes. Current Biology 24: $555-560$

Dalleau M, Andréfouët S, Wabnitz CCC, Payri C, Wantiez L, Pichon M et al. 2010. Use of habitats as surrogates of biodiversity for efficient coral reef conservation planning in Pacific Ocean Islands. Conservation Biology 24: 541-552.

Driver A, Sink KJ, Nel JN, Holness S, van Niekerk L, Daniels F et al. 2012. National Biodiversity Assessment 2011: an assessment of South Africa's biodiversity and ecosystems. Synthesis report. Pretoria, South Africa: South African National Biodiversity Institute and Department of Environmental Affairs.

Dulvy NK, Fowler SL, Musick JA, Cavanagh RD, Kyne PM, Harrison LR et al. 2014. Extinction risk and conservation of the world's sharks and rays. eLife 3: e00590.

Edgar GJ, Stuart-Smith RD, Willis TJ, Kininmonth S, Baker SC, Banks $S$ et al. 2014. Global conservation outcomes depend on marine protected areas with five key features. Nature 506: 216-220.

Faith DP. 1992. Conservation evaluation and phylogenetic diversity. Biological Conservation 61: 1-10.

Flynn DFB, Mirotchnick N, Jain M, Palmer MI, Naeem S. 2011. Functional and phylogenetic diversity as predictors of biodiversity-ecosystem-function relationships. Ecology 92: 1573-1581.

Forest F, Grenyer R, Rouget M, Davies TJ, Cowling RM, Faith DP et al. 2007. Preserving the evolutionary potential of floras in biodiversity hotspots. Nature 445: 757-760.

Froese R, Pauly DE (eds). 2016. FishBase. Available at http://www. fishbase.org [accessed October 2016]

Griffiths MH. 2000. Long-term trends in catch and effort of commercial linefish off South Africa's Cape Province: snapshots of the 20th century. South African Journal of Marine Science 22: 81-110.

Griffiths CL, Robinson TB, Lange L, Mead A. 2010. Marine biodiversity in South Africa: an evaluation of current states of knowledge. PLOS ONE 5: e12008.

Guindon S, Dufayard JF, Hordijk W, Lefort V, Gascuel O. 2009. PhyML: fast and accurate phylogeny reconstruction by maximum likelihood. Infection Genetics and Evolution 9: 384-385.

Heemstra P, Heemstra E. 2004. Coastal fishes of southern Africa. Grahamstown, South Africa: National Inquiry Services Centre (NISC) and South African Institute for Aquatic Biodiversity (SAIAB).

Heyns-Veale ER, Bernard ATF, Götz A, Mann BQ, Maggs JQ, Smith KM. 2019. Community-wide effects of protection reveal insights into marine protected area effectiveness for reef fish. Marine Ecology Progress Series 620: 99-117.

Hijmans RJ, van Etten J, Cheng J, Mattiuzzi M, Sumner M, Greenberg JA et al. 2015. Package 'raster': geographic data analysis and modelling. Available at https://CRAN.R-project.org/ package=raster [accessed May 2020].

Huang DW, Roy K. 2015. The future of evolutionary diversity in reef corals. Philosophical Transactions of the Royal Society B: Biological Sciences 370: article 20140010.

Ivanova NV, Zemlak TS, Hanner RH, Hebert PDN. 2007. Universal primer cocktail for fish DNA barcoding. Molecular Ecology Notes 7: 544-548.

James NC, van Niekerk L, Whitfield AK, Potts WM, Götz A, Paterson AW. 2013. Effects of climate change on South African estuaries and associated fish species. Climate Research 57: 233-248.

Kearse M, Moir R, Wilson A, Stones-Havas A, Cheung M, Sturrock $S$ et al. 2012. Geneious Basic: an integrated and extendable desktop software platform for the organization and analysis of sequence data. Bioinformatics 28: 1647-1649.

Kembel SW, Cowan PD, Helmus MR, Cornwell WK, Morlon H, Ackerly DD et al. 2010. Picante: R tools for integrating phylogenies and ecology. Bioinformatics 26: 1463-1464.

Kerwath SE, Winker H, Götz A, Attwood CG. 2013. Marine protected area improves yield without disadvantaging fishers. Nature Communications 4: article 2347.

Laikre L, Lundmark C, Jansson E, Wennerstrom L, Edman M, Sandstrom A. 2016. Lack of recognition of genetic biodiversity: international policy and its implementation in Baltic Sea marine protected areas. Ambio 45: 661-680.

Le Bagousse-Pinguet Y, Soliveres S, Grossa N, Toricesa R, Berdugo M, Maestre FT. 2019. Phylogenetic, functional, and taxonomic richness have both positive and negative effects on ecosystem multifunctionality. Proceedings of the National Academy of Sciences of the United States of America 116: 8419-8424.

Lindegren M, Holt BG, MacKenzie BR, Rahbek C. 2018. A global mismatch in the protection of multiple marine biodiversity components and ecosystem services. Scientific Reports 8: article 4099.

Ling SD, Johnson CR, Frusher SD, Ridgway KR. 2009. Overfishing reduces resilience of kelp beds. Proceedings of the National Academy of Sciences of the United States of America 106: 22341-22345. 
Lombard AT, Durbach I, Harris JM, Mann-Lang JB, Mann BQ, Branch GM, Attwood CG. 2020. South Africa's Tsitsikamma Marine Protected Area - winners and losers. In: Humphreys J, Clark RWE (eds), Marine protected areas: science, policy and management. Amsterdam, The Netherlands: Elsevier. pp 237-260.

Majiedt PA, Holness S, Sink KJ, Reed J, Franken M, van der Bank MG et al. 2019. Pressures on marine biodiversity. In: Sink KJ, van der Bank MG, Majiedt PA, Harris LR, Atkinson LJ, Kirkman SP, Karenyi N (eds), South African National Biodiversity Assessment 2018: Technical report, volume 4: marine realm. Pretoria, South Africa: South African National Biodiversity Institute.

Mann BQ (ed.). 2013. Southern African marine linefish species profiles. Special Publication 9. Durban, South Africa: Oceanographic Research Institute.

Mann BQ, Celliers L, Fennessy ST, Bailey S, Wood AD. 2006. Towards the declaration of a large marine protected area: a subtidal ichthyofaunal survey of the Pondoland coast in the Eastern Cape, South Africa. African Journal of Marine Science 28: 535-551.

Margules CR, Pressey RL. 2000. Systematic conservation planning. Nature 405: 243-253.

Mellin C, MacNeil MA, Cheal AJ, Emslie MJ, Caley MJ. 2016. Marine protected areas increase resilience among coral reef communities. Ecology Letters 19: 629-637.

Morley JW, Selden RL, Latour RJ, Frölicher TL, Seagraves RJ, Pinsky ML. 2018. Projecting shifts in thermal habitat for 686 species on the North American continental shelf. PLOS ONE 13: e0196127.

Mouillot D, Albouy C, Guilhaumon F, Lasram FBR, Coll M, Devictor $\mathrm{V}$ et al. 2011. Protected and threatened components of fish biodiversity in the Mediterranean Sea. Current Biology 21: 1044-1050.

Nielsen ES, Beger M, Henriques $R$, Selkoe KA, von der Heyden S. 2017. Multispecies genetic objectives in spatial conservation planning. Conservation Biology 31: 872-882.

Parravicini V, Villéger S, McClanahan TR, Arias-González JE, Bellwood DR, Belmaker J et al. 2014. Global mismatch between species richness and vulnerability of reef fish assemblages. Ecology Letters 17: 1101-1110.

Petchey OL, Gaston KJ. 2002. Functional diversity (FD), species richness and community composition. Ecology Letters 5: 402-411.

Phair NL, Toonen RJ, Knapp I, von der Heyden S. 2019. Shared genomic outliers across two divergent population clusters of a highly threatened seagrass. PeerJ 7: e6806.

Pimm SL, Jenkins CN, Abell R, Brooks TM, Gittleman JL, Joppa LN et al. 2014. The biodiversity of species and their rates of extinction, distribution, and protection. Science 344: article 1246752.

Pollock LJ, Rosauer DF, Thornhill AH, Kujala H, Crisp MD, Miller JT, McCarthy MA. 2015. Phylogenetic diversity meets conservation policy: small areas are key to preserving eucalypt lineages. Philosophical Transactions of the Royal Society B: Biological Sciences 370: article 20140007.

Posada D. 2008. jModelTest: phylogenetic model averaging. Molecular Biology and Evolution 25: 1253-1256.

Potts WM, Götz A, James N. 2015. Review of the projected impacts of climate change on coastal fishes in southern Africa. Reviews in Fish Biology and Fisheries 25: 603-630.

QGIS. 2015. QGIS Geographic Information System. Open-Source Geospatial Foundation Project. Available at http://qgis.org.

Roberts CM, O'Leary BC, McCauley DJ, Cury PM, Duarte CM, Lubchenco $\mathrm{J}$ et al. 2017. Marine reserves can mitigate and promote adaptation to climate change. Proceedings of the National Academy of Sciences of the United States of America 114: 6167-6175.

Rodrigues ASL, Greyner R, Baillie JEM, Bininda-Emonds ORP, Gittlemann JL, Hoffmann M et al. 2011. Complete, acurate, mammalian phylogenies aid conservation, but not much. Philosophical Transactions of the Royal Society B: Biological Sciences 366: 2652-2660.

RSA (Republic of South Africa). 2019. Regulation Gazette No. 42478. National Environmental Management: Protected Areas Act (Act No. 57 of 2003). Government Gazette, South Africa 647(42478).

Scheffer M, Vergnon R, van Nes EH, Cuppen JGM, Peeters ETHM, Leijs R, Nilsson AN. 2015. The evolution of functionally redundant species: evidence from beetles. PLOS ONE 10: e0137974.

Selig ER, Turner WR, Troëng S, Wallace BP, Halpern BS, Kaschner $\mathrm{K}$ et al. 2014. Global priorities for marine biodiversity conservation. PLoS ONE 9: e82898.

Sink KJ, Holness S, Harris L, Majiedt P, Atkinson L, Robinson T et al. 2012. National Biodiversity Assessment 2011: Technical report, volume 4: marine and coastal component. Pretoria, South Africa: South African National Biodiversity Institute.

Sink KJ, Sibanda SM, Fielding P, Skowno AL, Franken M, Harris LR et al. 2019. Ecosystem protection level. In: Sink KJ, van der Bank MG, Majiedt PA, Harris LR, Atkinson LJ, Kirkman SP, Karenyi N (eds), South African National Biodiversity Assessment 2018: Technical report, volume 4: marine realm. Pretoria, South Africa: South African National Biodiversity Institute.

Smith MM, Heemstra PC (eds). 1986. Smiths' sea fishes. Johannesburg, South Africa: Macmillan.

Spalding MD, Fish L, Wood LJ. 2008. Toward representative protection of the world's coasts and oceans - progress, gaps, and opportunities. Conservation Letters 1: 217-226.

Taunton-Clark J, Shannon LV. 1988. Annual and interannual variability in the south-east Atlantic during the 20th century. South African Journal of Marine Sciences 6: 97-106.

Teske PR, von der Heyden S, McQuaid CD, Barker NP. 2011. A review of marine phylogeography in southern Africa. South African Journal of Science 107: 43-53.

Toms JA, Compton JS, Smale M, von der Heyden S. 2014. Variation in palaeo-shorelines explains contemporary population genetic patterns of rocky-shore species. Biology Letters 10: article 20140330.

Turpie JK, Beckley LE, Katua SM. 2000. Biogeography and the selection of priority areas for conservation of South African coastal fishes. Biological Conservation 92: 59-72.

Venter JA, Mann BQ. 2012. Preliminary assessment of the surf-zone and estuarine linefish species of the Dwesa-Cwebe Marine Protected Area, Eastern Cape, South Africa. Koedoe 54: $1-10$.

von der Heyden S. 2017. Making evolutionary history count: biodiversity planning for coral reef fishes and the conservation of evolutionary processes. Coral Reefs 36: 183-194.

Wiedmann MA, Aschan M, Certain G, Dolgov A, Greenacre M, Johannesen $E$ et al. 2014. Functional diversity of the Barents Sea fish community. Marine Ecology Progress Series 495: 205-218.

Winter M, Devictor V, Schweiger O. 2013. Phylogenetic diversity and nature conservation: where are we? Trends in Ecology and Evolution 28: 199-204.

Wright D, Bishop JM, Matthee CA, von der Heyden S. 2015. Genetic isolation by distance reveals restricted dispersal across a range of life-histories: implications for biodiversity conservation planning across highly variable marine environments. Diversity and Distributions 21: 698-710. 